Pakistan Journal of Humanities and Social Sciences

July - September 2018, Volume 6, No. 3, Pages 357 - 369

\title{
A Review on Human Development Index
}

\author{
Anam Javaid ${ }^{1}$, Atif Akbar ${ }^{2}$, Shahbaz, Nawaz ${ }^{3}$ \\ ${ }^{1}$ Lecturer, Department of Statistics, The Women University Multan, Pakistan \\ ${ }^{2}$ Assistant Professor, Department of Statistics, Bahauddin Zakariya University Multan, \\ Pakistan \\ ${ }^{3}$ Visiting Lecturer, Bahauddin Zakariya University Multan, Pakistan \\ Email: anamjavaid0786@yahoo.com
}

\begin{abstract}
Human development index is considered as very important for economy as by looking on it, development level of any country can be seen. It is based on education Index, health index and on GDP so for the purpose of analyzing the developing level of a country in different years, it is important to consider its HDI. In literature, Different authors have worked on
\end{abstract} HDI. The current paper summarizes the work by different authors so from this review paper the work that had been done on HDI can be seen.

Keywords: Human Development, Multivariate analysis, Economy, Pakistan

JEL Classification Codes: G12, G21, G32, E43

\section{Introduction}

Human Development includes the study of human condition. It does not only deals with rise or fall of national income or economic growth but also deals with the choices of people and expansion of choices which they have in their life. It also deals with the value and improvement of human condition. It scatters the attention of distribution of commodities and services and sees the effect of this on human decision. By developing human capabilities, we can make growth so that a person may be able to get power to live a healthy life, to get education, to get the approach to resources and to be able for the social sources which are necessary for a proper standard of living and also can make a person be able to participate in life of community. Human development may be defined as a process of provide enlarger freedom to people and give them opportunities for their well-being. It means freedom which a common man should have to decide about his own living. Six basic supports of human development can be describes as equity, sustainability, productivity, empowerment, cooperation and security where Equity means men and women have same rights for everything like in education, in health care etc. Sustainability means that all the persons have 
rights to earn their living so that they can be able to access the more even distribution of commodities. Productivity deals with participation of people in income generation, i.e., people should give full participation in generating income and government should make more effective social programs for its people. Empowerment means the freedom of people those effects on development and decision which influence their lives. Cooperation specifies the meaning of mutual group improvement and social source and participation in communities. Security offers development opportunities to people and provide safety so that suddenly in future, they may not disappear so basically Human Development Index can be defined as an index number which measures the achievement of country on average in health, knowledge and income which are three basic features of human development. Human development not only counts economic growth but include people and their capabilities in development of a country.

The objective of the current study is to explore the determinants of human development. Human development is to be monitored for different aspects of human life, i.e. health, education, facilities, luxuries, type of dwelling, government utility store, and type of fuel used for cooking.

By looking at the human development level, the development level of any country can be seen so it is important to know its determinants. From different standpoints, different contributions are available in literature for determinants of human development. The current study focused on the study related to Human Development Index in literature so that the importance of HDI can be seen in different countries. By comparison and discussion of different studies, the current study will provide the comprehensive insight concerning the human development that will provide the healthy contribution in the literature.

\section{Review Analysis}

Akbar and Altaf (1995) studied that how the utility variables like gas, water and electricity effects on the dwelling unit's rent in the squatter arrangement of Karachi. They presented practical support on market parameters that could described the hedonic price formation for housing in low income localities of Karachi. Hedonic studies of housing markets had been done in many developing cities due to World Bank sponsored. They took data from the Applied Economics Research Centre (university of Karachi) that was prepared for the Karachi Master Plan and used Rent as a dependent variable and utility services like water, electricity, gas and structural qualities like wall quality and roof quality and number of rooms, year of residence, and population as an independent variable. They applied regression 
in both linear and in semi log form and except roof and population density and found all the variables as significant. After calculating all the results of above regressions, they also compared the result of Pakistan with EL Salvadar (which was computed by Quigley in 1980) by comparing the coefficients of Semi Log GLS estimation and t- statistics.

Khan (1999) studied in his research about the education expenditure by taking as GDP's percentage had increased about $0.2 \%$ over first phase of SAP (Social Action Program) But it declined for 1998-1999 to the pre-SAP level. SAP main aims were the protection of social and expenditures of sectors and to guarantee that these kind of expenditures results inclosing of Gender, Income and of provincial gaps for accessing the facilities of social sector. He showed evidence that the poorest continued to be excluded from schooling because they were mostly likely to drop out even if they attend it. Over the first SAP period, net enrolment rates of girls and boys declined actually. The data was taken from economic survey (1998-1999) of Pakistan and found that the education expenses as GDP percentage from 1988-1989 to 1998-99 also he calculate the rural student teacher and student institution ratio by gender, time and by their level. He found gross primary enrolment rates of females between the years 1991 and 1995-96 based on PIHS (Pakistan Integrated Household Survey) data. From sector of education, they showed some success in the education sector had been there in duration of SAP period. The aggregate analysis suggested about these expenses had not been enough for reducing boys and girls congestion at middle level. Pakistan had made some progress in schooling also dropping out was no longer taken to be as a problem as it was before. Of SAPP-I (1993-1996) last three years, there had been improvement in maintenance the school buildings and availability of books, Improvement in number of staff members and classrooms. Finally, it was noted an increase in gross enrolment rate of girls belonging to rural areas with including the girls belonging to lowest income group. Non-government enrolments raised by $61 \%$ and $13 \%$ for girls and for boys as compared to $23 \%$ and $4 \%$ respectively for government school enrolment growth rates. SAP had facile in one of key objective of talking about the income gap in social sector establishment because the probability for dropping out increases as household income declines.

Holmes (1999) contributed to human index by analyzing the demand of child schooling in Pakistan. He used Pakistan Integrated Household Survey (PIHS 19991) for this purpose. He also focused on two potential sources of bias in estimation of demand for schooling. A censoring bias occurred when could not differentiate between currently enrolment children and those who had done their schooling subject and selection bias 
occurred when he eliminated the children who had left household from samples, if decision was to leaving home and for attending school were connected. He computed the censored ordered probit analysis for year of schooling. He also computed OLS and Tobit analysis for comparison purpose. As a result, he concluded that that it took additional four years for education of father for moving a boy in grade one by OLS and ordered probit estimates. While according to the censored ordered probit analysis, it took less than half a year of father's schooling to achieve same changes. Sample that consisted only home-resident children introduced bias in OLS and estimates of censored probit for girls and boy's schooling demands. Primary school distance did not effect on attainments while distance to middle school and to secondary school significantly effected on final schooling level.

Luby and Rahbar (1999) estimated that whether the distance from health service affected on availability of government health facility rather than the private services for under five year children. They took three most common serious infant diseases like fever, diarrhea and upper respirational infections for analysis purpose and analyzed the household survey data of 1992 and 1993 in Thatta (a rural district in Pakistan) and applied multiple logistic regression and found adjusted odds ratio. They studied a small part of Thatta Health survey (1988) which was conducted by Aga Khan University and the average use of government health facility was found to be 0.25 visits per person per year. Now the above study of 1999 found that out of 691 children of less than five year, $85 \%$ used private or government health facilities. Children who lived in less than four $(\mathrm{km})$ from government health facility used as $22 \%$ less service from the children who lived $4 \mathrm{~km}$ or more away from the government health facility. Then they found results after controlling distance effect from private health facility and cost for treatment. They found that children who lived less than $4(\mathrm{~km})$ from government facility no more used government facility than from those who lived $4(\mathrm{~km})$ or more away. As a result, they suggested that factors other than distance were basic determining factors for use of government health facilities of treating children in Thatta district

Glick and Sahn (2000) extended the above studies by investigating the factors of multiple schooling indicators like grade attainment or current attainment and the withdrawal from school, which effected on gender difference in schooling. They analyzed it in West Africa for poor urban environment by taking data from a survey of Conakry in 1990.they used Binary and Probit models for analysis and showed the parent's education as positively related with child's schooling. Mother's education found to be positively related with the grade attainment for girls and enrolment but had not effects on boy's education while education of 
father found to be effected on both boys and girl's education. Increase in income and siblings under five year had positive and negative effect on girl's education attainment respectively. Education intervention on girls could decrease gender gap in schooling.

Gupta et al. (2002) analyzed the efficiency of health and education facilities after government spending on them in developing countries. They used cross sectional data for 50 developing countries and applied regression model by taking social indicator (which reflected education achievement or health status) as a dependent variable and showed that as the government spending increased for making the improvement in health and education facilities, public expenditure increased on both. They showed that as public expenditure on primary and secondary education increased, education attainment increased and infant mortality rate decreased by increasing health care expenditure. The findings were that the education regression as Robust for different specifications but relationship between health care spending and mortality rate was found to be weaker.

Chaudhuri and Pfaff (2003) analyzed the fuel choice and its effect on environment in developing countries. As the choice of fuel use also effected on household's health. They used household data from Pakistan Integrated Household Survey (PIHS) of 1991 and estimated for dirty (traditional) and clean (modern) fuel use, they estimated Engle curves and used generalized Tobit approach for estimation of Engle curve and found that as income of household increased, they started use cleaner modern fuel instead of traditional Biomass fuels and the Engle curves for at least over the income range had U-shaped

Heltberg (2004) examined factors about fuel used in household and for fuel switching. For this purpose, he used household survey data taken from Brazil, Ghana, Guatemala, India, Nepal, Nicaragua, South Africa, and Vietnam. He applied regression analysis on fuel use in rural and urban areas and analyzed solid fuel and non- solid fuel use choice in developing countries. He used explanatory set of variables that could effect on fuel choice. He used Logit and Probit regression analysis and indicated the solid fuel use as negatively related with expenditure in both urban and rural areas and found modern fuel as positively correlated with electrification of the household. Tap water found to be associated with fuel switching. Household size also positively effected on the number of fuel to be used and as the education level increased, more chances of modern fuel were found as compared to solid fuel use.

Lewis et al. (2004) extended the above studies by examining the health care admittance and the use of public and private sectors. They wanted to find the determinants of 
health seeking behavior. For this purpose, they used Multivariate analysis and used data from different surveys such as annual national multipurpose survey (EHPM), focus group surveys (FGS) and from a survey of 315 women which participated in focus group. They took two dependent variable separately as 'seeking care vs. not care' and 'seeking public vs. private care' with different independent variable as age cohort, education, medical cost, different type of diseases etc. As a result they found the value of public services where they meet the need of population. People preferred the private health care services even those who belonged to low income groups. Similarly they generally preferred higher level health facilities.

Ahamd and Arshad (2007) analyzed the human development for Pakistan by taking micro-level household data from areas of rural and urban Pakistan. They estimated Engel equations for 22 commodity groups with quadratic spline specification. This study found that across income ranges the flexibility in results produced numerous interesting changing patterns for classification of goods into necessities and luxuries. The result suggested that for budget allocation and for household's welfare that belonged to different income classes, uniform tax structure will have fluctuating inferences. Engel curve [following Engel (1857)], the relationship between total expenditure and the expenditure devoted to purchase of a specific consumer good was considered as starting point for the analysis of household budget. After the analysis, the results showed that among the rural and urban households, elasticity for total expenditure of all 22 groups of commodity were positive for all income levels but the middle income class considered wheat as inferior good. Urban households considered wheat, health and housing as complete necessities while households from rural areas considered besides clothing and footwear, wheat, housing and tobacco as complete necessities. Otherwise for goods that had higher health value like health care, dairy, sugar, edible oils, meats, poultry and fish. The urban households tend to had stronger preference.

Shamim and Ahmad (2007) extended the above studies by analyzing household consumption pattern in rural and urban areas. They used data from Household Integrated Expenditure Survey (HIES) for year 2001-2002 and took 18 commodities group and estimated Engle curves by spline quadratic expenditure system. They explained consumption pattern by age and sex of the household. After finding the results, they conclude that Engle curve consumption categories like vegetable, fruits, spices, and footwear had been considered as necessities and housing and health as luxuries in urban areas. While in rural areas, people considered food, electricity, entertainment, transport, education, textile, durables and other non-food items as luxuries. Low income groups in urban areas considered vegetable, fruits, 
fuel and lighting, Clothing as luxuries while high income group in urban areas considered all above as necessities

Purohit (2007) analyzed the factor of relationship between human development and income. He analyzed data of three Indian states Orissa, Karnataka and Maharashtra which represented poor, middle income and high income states respectively. $\mathrm{He}$ found by comparison of different level states that in richer state, development of poor district had ignored and performed linear Regression analysis and log linear regression analysis for each state to see the insufficiency of social sector interferences and pointed out the sensitivity differences of human development beyond selected states. Many studies had been done at inequality and its causes for India at state level but no study had been done at district level. He found the significant inference for education, health and economic foundation planning policies for human development of the above states. He confirmed the Haan and Dubey (2005) finding. The two- way regression analysis showed that by using a more suitable development strategy, income of state could be enhanced. Rich and poor states also varied in duration and parameter. After adopting an ongoing process at district level over a long period of time, inequality could be minimized by applying social and economic infrastructure policies.

Filmer (2008) extended the above studies by analyzing the data from 14 household surveys taken from 13 developing countries. He found that $1-2 \%$ of population had incapacities. Mostly association was appeared in lower educational achievement among disabled adults. The objective for his study was to see the association of disability with household economic status between the youth of 6 to 17 years old and to see the relationship among disability, poverty and education achievement among adults. As a result, he found that disabled children were lived in richer or poorer household but disabled adults were in poorer households and they had lower educational attainments. The children with disabilities were less likely to start school while for some countries they had lower transition rates. So, there was an association between disability and long-run poverty in developing countries. So, there is a need to increase enrolments of children and youth with disabilities.

Huisman and Smits (2009) explored the enrolment in Primary School for 30 Developing Countries primary school enrolments. They used data of 220,000 children for 340 districts in 30 developing countries. Most comparative studies focused also on micro level or macro level in developing countries but regional level had been neglected in most of the previous research. So, in their study the objective was to see the household and district-level 
determinants of young children (aged 8-11) enrolment in education in developing countries. They used bivariate and multivariate logistic regression analysis and used "odds of being in school as a dependent variable" by taking different demographic factors, socio-economic factors, educational facilities, culture and economic factors as dependent variables. As a result, they found that the socio- economic factors had significant effect on student's enrolment. Children with more siblings had less chance for enrolment in a school and if female teachers were available in district level. Then there were high chances for girl's enrolment in a school at district level. Long distance found to be a big obstacle in enrolment of young children in a school. In rural Ares, if the father had secondary or higher education there were high chances for girls enrolment and if father had non-manual occupation, there were high chances for boy's enrolment in a school.

Dasgupta et al. (2009) analyzed that whether satisfaction data could serve as a credible symptom of quality. For this purpose, they used satisfaction data about health and education from 2006 second round of the Governance and Decentralization survey. This was conducted in Indonesia and used an expectation disconfirmation model, which measures the user's compensation with the improved facility and also measures the positive difference between the actual quality of the facility and users expected level of quality. They fitted a two-stage Heckman selection model separately for health facilities and school facilities satisfaction. After the results, they found that many factors other than quality of facilities also had significant role on household's satisfaction. They found Public school satisfaction as significantly associated with household location and through satisfaction level in poor district.

Idress and Ahmad (2010) extended the above previous studies and found that the consumption expenditure in Pakistan improved slightly between 1992/93 and 2004/05. They also found that food inequality in consumption was lower than as compared to non-food consumption. Household on education had been more unfairly distributed than overall consumption expenditure while on other side, health care expenditure in urban areas had been distributed relatively more evenly in recent years and in rural areas it had remained persistent and slightly higher. They used GINI coefficient as a measure of inequality where 0 represent perfect equality and 1 represent perfect inequality by taking data from HIES. This was a country wide survey based on 14000 households on consumption expenditure. As a result, After applying GINI Index, they found at country level, the cereals and grain's concentration ratios, other food items, apparel textile, foot wear and personal effects, and fuel and lighting had persisted lower than from overall GINI Index for consumption of household, On the other 
hand, the concentration ratio of house rent, furniture, transport and various expenditure had remained greater than from overall GINI Index household consumption.

Zhao and Glewwe (2010) extended the study by examining school attainment in poor rural area of China. They took Household Survey data from Gansu (Province in Northwest China) and applied censored ordered probit regression for estimation of mathematical quantity of year of schooling. They took "grade for dropping out" as a dependent variable and other factors effecting on the dropping out grade as independent variables. They also compared lower secondary school with lab and without lab. After the empirical results, they found the mothers education, children's nutritional status and household income as positively significant with children's enrolment. In lower secondary school, science lab and teachers experience also positively effected on enrolment.

Faridi et. al. (2010) extended the above studies by examining the impact of education on employment in Pakistan. They collected primary data for the analysis from rural area of district Bahawalpur and used Logistic regression for analysis and collected data of 494 workers (labor force) aged 15-64 for year 2008-2009. They used different demographic, economic and human capital related variables. They found that education at all level had significantly impact on employment except education up to middle level. Closed relative's education and health status had positive significant effect on worker's employment. Number of dependents and household size were found to be significantly effected on employment.

Abbas and Hiemenz (2011) extended the previous studies by analyzing the health care spending in Pakistan using the time series data from 1972-2006 on economics, demographic, social, and political variables. They found after applying unit root test on data from 1972-2006 the all variables as first difference stationary and found possible long run relationship and short run relationship between expenditures on health care with both income and non income variables after co integration and VECM-Urbanization inversely affected on public health care expenditures in long run. But in short run, this variable was non-significant. Similarly, unemployment had a significantly negative effect on health care expenditure per capita in long run. Income elasticity of health care expenditures in their results was less than unity which was contradiction with most previous studies results.

Peykarjou et al. (2011) extended the above studies by evaluating the association between health and economic growth in Organization Islamic Conference member. They took time series data for years 2001-2009 and took elements that effected on economic growth like fertility rate, life expectancy etc. they applied semi log regression model on panel data. After 
taking different micro and macro factors effecting on health they showed the life expectancy as positively significant on economic growth of OIC member states. Fertility rate had negatively significant impact on economic growth.

Ahmad and Riaz (2012) extended the above previous studies by estimating poverty in Pakistan using annual time series data from 1974 to 2009. They used four independent variables education, economic growth, Inflation and unemployment. After applying methodology ADRL model, they found that poverty and education level was positively and statistically significantly related in short run and in long run. It was may be because of macroeconomic variables that there was a positive relationship of education with poverty. Economic growth has negative significant impact on poverty in long run and short run. But inflation was insignificant both in long run and short run while unemployment was inversely related with poverty in the long run and short runs.

Ajmair and Akhtar (2012) analyzed the factors effecting on household consumption. They examined the case study of district Bhimber, AJK (Azad Jammu Kashmir) by taking primary data. For this, they took different factors effecting on household consumption like age, family size, income and basic needs and proved the theory of Keynes. They applied multiple regression economic models by taking household consumption as a dependent variable and other factor effecting on household consumption as independent variables. They found the income, gender, family size, basic needs, education, family structure as positively related but age as negatively related with consumption because as age increased, saving increased so consumption decreased and the people belonging to higher families had higher consumption pattern.

\section{Methodology}

From the above review analysis, different methodologies regarding HDI can be observed in literature as many authors has used regression analysis like OLS, multiple regression, bivariate or multivariate logistic regression, semi log linear regression model, two way regression analysis, logit and probit regression model and log linear regression analysis to study the significant factors related to HDI also GINI index, Engle curves, two-stage Heckman selection model has been used by some researchers for HDI. 


\section{Concluding Remarks}

From the above analysis it can be concluded that for human development there is a need to keep in mind all the above factors like education, health, type of dwelling, facilities and luxuries. In a country human development level will depend on the level of above factors, as these factors will be on high level, human development level will also be high of that country. So, it is important to consider all the above factors in a country to make its development level high because without these factors, no country can be developed. In developing countries the basic reason for low development is that they are far behind from these concerns as compared to the developed countries so for increasing a development level of country, future policies should be made in this way that cause an increase in these facilities related to HDI. 


\section{References}

Abbas, F. and Hiemenz, U. (2011). Determinants of Public Health Expenditures in Pakistan. Zentrum fur Entwicklungsforschung (ZEF); 158, 1-30.

Ahmad, E. and Arshad, M. (2007). Household Budget Analysis for Pakistan under varying the Parameter Approach: Pakistan Institute of Development Economics; 41.

Ahmad, K. and Riaz, A. (2012). An Econometric Model of Poverty in Pakistan: ADRL Approach to Co-integration. Asian Journal of Business and Management sciences; 1 (3), 75-84.

Ajmair, M. and Akhtar, M. (2012). Household Consumption in Pakistan (A Case Study of District Bhimber, AJK).European Journal of Scientific Research. ISSN 1450-216X Vol.75 No.3, 448-457.

Akbar, M. and Altaf, A. (1995). A Rent Hedonic Model of the low Income Housing Market in Karachi. Pakistan Economic and Social Review; 33(1/2 ), 79-90.

Chaudhuri, S. and S. P. Pfaff, A. (2003). Fuel-choice and Indoor air Quality: A householdlevel Perspective on Economic Growth and the Environment.1-34.

Dasgupta, B. Narayan, A. and Skoufia, E. (2009). Measuring the Quality of Education and Health Services: The Use of Perception Data from Indonesia. Policy Research working Paper 5033, 155.

Faridi, M. Z. Malik, S. and Ahmad, R.I. (2010). Impact of Education and Health on Employment in Pakistan: A Case Study. European Journal of Economics, Finance and Administrative Sciences ISSN 1450-2887 Issue 18 (2010).

Filmer, D. (2008). Disability, Poverty, and Schooling in developing countries: Results from 14 household surveys. The World Bank Economics Review; 22 (1), 141-163.

Glick, P., and Sahn, D. (2000). Gender and education impacts on Employment and Earnings in a Developing Country: the Case of Guinea. Economic Development and Cultural Change; 45(4), 793-823.

Gupta, S. Verhoeven, M. Erwin R. Tiongson, E. (2002). The Effectiveness of Government Spending on Education and Health Care in Developing and Transition Economies. European Journal of Political Economy; 18, 717-737.

Heltberg, R. (2004). Fuel switching: Evidence from Eight Developing Countries. Energy Economics; 26, 869-887.

Holmes, J. (1999). Measuring the Determinants of School Completion in Pakistan: Analysis of Censoring and Selection Bias. Economic Growth Centre: 794, 1-63. 
Pakistan Journal of Humanities and Social Sciences, 6(3), 2018

Huisman, J.and Smits, J. (2009). Effects of Household and District Level Factors on Primary School Enrolment in 30 Developing Countries. World Development; 37 (1), 179-193.

Idress, M. and Ahmad, E. (2010). Measurement and Decomposition of Consumption Inequality in Pakistan. The Lahore Journal of Economics; 15(2), 97-112.

Khan, S.R. (1999). An Overview of Basic Education Under The Social Action Plan in Pakistan. Sustainable Development Policy Institute (SDPI); Research report series: $22,1-10$.

Lewis, M. Eskeland, G. and Valerezo, X. T. (2004). Primary health care in practice: is it effective? Health Policy 70 (2004) 303-325.

Noorali, R. Luby, S. and Rahbar, M. H. (1999). Does Use of a Government Service Depend on Distance from the Health Facility?.Health Policy and Planning; 14(2), 191-197.

Peykarjou. Gollu, R. B. and Gashti, H.P. (2011) Studying the Relationship Between Health and Economic Growth in OIC Member states. 3(8), 1-14

Purohit, B. C. (2007). Health and Human Development at Sub-state Level in India. The Journal of Socio-Economics; 37, 2248-2260.

Shamim, F. and Ahmad, E. (2007). Understanding household consumption patterns in Pakistan. Journal of Retailing and Consumer Services; 14, 150-164.

Zhao, M. and Glewwe, P. (2010). What determines basic school attainment in developing countries? Evidence from rural China. Economics of Education Review; 29, 451460. 